\title{
Editor's Comment
}

I have had a long and gratifying term as Editor of Stereotactic and Functional Neurosurgery, but it is now time to make a change. Within the next few months, we will publish the Proceedings of the Meeting of the World Society for Stereotactic and Functional Neurosurgery that was held in Adelaide, Australia, in September 2001, which will conclude my activities as Editor.

As you know, David W. Roberts has been Associate Editor for the past 3 years. I very much appreciate his help and advice during that time. Dr. Roberts will assume the role of Editor immediately after publication of the WSSFN Proceedings. I will stay on as Associate Editor for now to assist with the transition.

Since we are already in the process of editing the issues to appear following the Proceedings issues, please send manuscripts to be considered for publication to Dr. Roberts, as indicated in the Guidelines for Authors, and address inquiries about publication to him.

I would like to thank all members of the present and past Editorial Boards for their help, as well as members of the various Stereotactic Societies and subscribers for your involvement. I would particularly like to thank S. Karger AG and members of the Karger family for their support throughout the years.

Philip L. Gildenberg, Houston, Tex. 